\title{
HEIDEGGER Y EL “ENREDO” DE LA FILOSOFÍA CON LA POLÍTICA: SOBRE SU ORIGEN ROMÁNTICO-PLATÓNICO
}

\author{
Diana del Carmen Aurenque Stephan \\ Albert-Ludwigs-Universität Freiburg \\ diana.aurenque@googlemail.com
}

\begin{abstract}
Resumen
En el artículo se interpreta el "enredo" de la filosofía de Heidegger con el nacionalsocialismo desde una perspectiva distinta a la de sus críticos y defensores. Ciertamente, la "política" heideggeriana está en relación con el nacionalsocialismo, mas ésta no se identifica ni con la ideología nazi ni con ninguna política tradicional. Su "política" es expresión de un proyecto filosófico-romántico relacionado con una determinada lectura de Hölderlin y con una concepción platónica de la filosofía. Reconocer el carácter metapolítico de su pensar exige repensar el "caso Heidegger" desde un ámbito que pregunte por la relación entre la filosofía y el mito.
\end{abstract}

Palabras Clave: Heidegger, nacionalsocialismo, espíritu, Hölderlin, círculo de George, von Hellingrath.

\section{Abstract}

This paper interprets the "entanglement" of Heidegger's philosophy with National Socialism from a perspective which differs from that of his critics and defenders. Heidegger's "politics" is indeed connected with National Socialism, but it identifies itself neither with the Nazi ideology nor with traditional politics. His "politics" is the expression of a philosophical-romantic project related to a particular reading of Hölderlin and to a Platonic conception of philosophy. To recognize the meta-political nature of his thinking requires rethinking the "Heidegger affair" from a standpoint that asks for the relationship between philosophy and myth.

KeYwords: Heidegger, National Socialism, spirit, Hölderlin, George's circle, von Hellingrath.

Preguntar por la relación entre la filosofía de Heidegger y la política se vincula siempre y necesariamente a la pregunta por la posible conexión entre su pensar y el nacionalsocialismo. Dicha pregunta no es arbitraria, sino más bien necesaria. Pues no resulta fácil comprender que un genio tal de la filosofía, de cuyo pensar son herederas las filosofías de Lévinas, Derrida, Gadamer, Arendt, Foucault, Jonas y tantos otros, haya tomado partido en una de las empresas más traumáticas de la historia del siglo XX. 
El desarrollo del llamado "caso Heidegger" es conocido. El 21.04.1933, Heidegger es elegido de forma casi unánime rector de la Universidad de Friburgo. Poco tiempo después, a saber el 1.05.1933, Heidegger se convierte en miembro oficial del partido nazi (NSDAP). En su famoso discurso rectoral La autoafirmación de la universidad alemana, así como también en una serie de otros discursos que Heidegger sostiene durante su período como rector, no solo pone de manifiesto públicamente su simpatía hacia el nacionalsocialismo, sino que también realiza una clara vinculación entre su filosofía y la política. Sin embargo, su período rectoral durará menos de un año. Heidegger rechazará el curso que ha tomado la "revolución nacionalsocialista" y el 12.04.1934 presenta su renuncia. Si bien su renuncia significa un quiebre oficial con la política nazi dentro de la universidad, Heidegger seguirá impartiendo clases ininterrumpidamente hasta el año 1945.

Tras el término de la guerra, Friburgo se halla ocupado por las fuerzas militares francesas y con ello comienza el proceso de desnazificación. La administración militar francesa forma una comisión de depuración al interior de la Universidad de Friburgo con la misión de determinar el grado de compromiso y de responsabilidad que tuvieron sus integrantes durante el período de la Alemania nazi. Heidegger se presentará el 23.07.1945 por primera vez ante esta comisión. Con la premisa de que “tras 1934 él [Heidegger] no puede ser llamado 'Nazi”" (Ott 1992, p. 306) la comisión ordena que Heidegger debe jubilarse anticipadamente, pero se le permite continuar manteniendo su cátedra. Sin embargo, el Senado universitario no aceptará dicho dictamen y el 21.11.1945 lo someterá a revisión. El arzobispo Conrad Gröber y el antiguo amigo de Heidegger, el filósofo Karl Jaspers, le entregan al Senado testimonio escrito sobre la personalidad y calidad moral de Heidegger. Como es sabido, es justamente el dictamen de Jaspers lo que es decisivo para que el Senado establezca el 19.01.1946 la jubilación como académico (Emeritierung) de Heidegger, la prohibición de enseñanza (Lehrverbot) y su alejamiento de las actividades públicas universitarias (Ott 1992, pp. 315-320). Mas, en agosto del mismo año se revocará la sentencia dada en enero y con ello se obliga a Heidegger a una jubilación que le quita la calidad de profesor universitario (Pensionierung). Recién en el año 1950, la prohibición de ejercer docencia será revocada. A Heidegger se le restituye la jubilación como académico y se le permite nuevamente impartir clases. Con este hecho, la filosofía de Heidegger vuelve a estar en boga. El aula donde él presenta su primera lectura pública en Friburgo durante el semestre de verano de 1952 titulada Qué significa pensar? (Was heißt Denken?) estaba repleta de estudiantes. El interés por su filosofía, por oír a Heidegger tras los años de silencio obligado, era creciente. A diferencia de Francia, donde la filosofía de Heidegger ya desde mediados de los años cuarenta tenía un enorme impacto, tal como informa Gadamer, es recién durante los años cincuenta que en Alemania comienza una reapertura hacia la filosofía heideggeriana (Gadamer 1999, p. 262).

Pese a la "vuelta de Heidegger" a la publicidad filosófica, su pasado nazi no es olvidado. Uno de los primeros y más famosos críticos de Heidegger es Jürgen Habermas. Pocos años tras la rehabilitación de Heidegger, a saber, en el año 1953, el para entonces veinteañero Habermas escribe un artículo en el F.Z.A [Frankfurter 
Allgemeine Zeitung] en el que Habermas no solo recuerda el pasado nazi de Heidegger, sino que además le crítica que en la publicación de su cátedra de 1935 Introducción a la metafísica, publicada ocho años después, aún se encuentre la polémica sentencia sobre "la verdad y la grandeza interna de ese movimiento" (GA40, p. 208). La polémica en torno al "caso Heidegger" volverá a estallar en el año 1986 tras las publicaciones tanto de Víctor Farías, Heidegger et le nazisme y de la biografía de Heidegger escrita por Hugo Ott que aparece en el año 1987, Martin Heidegger: Unterwegs zu seiner Biographie. Dichos trabajos tuvieron un enorme impacto, dado que a través de ellos fueron puestos al descubierto una serie de documentos hasta el momento desconocidos, que vertían nuevas luces sobre el "caso Heidegger". Desde entonces, la polémica en torno a la relación de Heidegger -y con ello, de su filosofía- con el nazismo no ha cesado. Uno de los trabajos más recientes en esta materia es el libro de Emmanuel Faye, Heidegger. L'introduction du nazisme dans la philosophie publicado en el año 2005. Faye sigue la línea de Farías y acusa a la filosofía de Heidegger de encubrir un hitlerismo, o mejor dicho, de ya no ser siquiera filosofía. Dos años tras la publicación del libro de Faye, aparece el compendio Heidegger à plus forte raison, en el que once autores, entre ellos el conocido defensor de Heidegger François Fedier, se dedican a descomponer y a analizar el libro de Faye con el objeto de mostrar que el texto está plagado de errores y de malas interpretaciones.

En vistas de lo hasta aquí dicho, desde ya es importante tomar posición en el asunto. El presente artículo no toma partido ni por los críticos-enemigos de Heidegger ni por sus defensores. Pues, como dice Gadamer: "Cuando se cree saber de sí mismo, que uno está 'contra' Heidegger -o cuando se está 'a favor' de él-, uno se pone en ridículo" (1999, p. 263). Mi propósito consiste en mostrar que si bien la filosofía heideggeriana se relaciona a una cierta "política", ésta no es política en sentido tradicional, y por tanto no es legítima su identificación ni con un mero hitlerismo ni con la ideología nacionalsocialista. No obstante, ello no quiere decir que su pensar político no esté en relación con el nacionalsocialismo. El mismo Heidegger confirma esto cuando en su carta del 15.12.1945 dirigida a la comisión de depuración sostiene: "no era mi propósito entregar la universidad a la doctrina del partido, sino, por el contrario, tratar de poner en marcha una transformación espiritual [geistige Wandlung] en el nacionalsocialismo y en relación con este" (GA16, pp. 410-11). La situación es paradójica y por ello compleja: la filosofía "política" heideggeriana tiene relación con el nacionalsocialismo, pero no se reduce a este último. Por ello, es central descubrir que si bien a partir de la subida al poder del nacionalsocialismo Heidegger se interesa por primera vez y públicamente por la política, su propósito no es el mero propagar la ideología nazi a través de su filosofía. Tal como reconoce el propio Hermann Heidegger -hijo de Heidegger y administrador de la Gesamtausgabe-, es innegable el "enredo" [Verstrickung] (GA16, p. 835) de Heidegger con el nacionalsocialismo. No obstante, tal enredo no debe ser comprendido como una traición a la filosofía; no se trata de que la filosofía haya sido puesta al servicio de fines políticos. Las razones por las que Heidegger vincula la filosofía a la política no son políticas sino, como veremos, filosófico-románticas. 


\section{Heidegger y la politica hasta 1933}

Quien conoce la filosofía del joven Heidegger sabe que en ella el tema político carece de importancia alguna. En ninguna de sus lecciones hasta el año 1933, Heidegger demuestra algún tipo de interés por la filosofía política. Incluso en sus lecciones tempranas sobre Aristóteles y Platón se observa que Heidegger pasa completamente por alto la dimensión política que pertenece intrínsecamente a dichas filosofías. Por tanto, para sus discípulos -como por ejemplo Hermann Mörchen y Max Müller (Safranski 2006, p. 258)- no es sino sorprendente que Heidegger tome partido público por el nacionalsocialismo. En su concepción temprana de la filosofía e incluso hasta Ser y tiempo se observa un claro predominio del individuo por sobre la comunidad. Heidegger entiende la existencia como el fundamento óntico desde el cual surge todo preguntar ontológico fundamental; mas, dicha existencia no se vincula a una pluralidad, ella no refiere a la humanidad en general, sino que ésta es pensada desde su individualización radical. Para Heidegger, la existencia es siempre la propia y respectiva existencia de cada cual. Por ello, no resulta fácil entender el tránsito que tiene su pensar desde una tal visión individualizada de la existencia hacia el establecimiento de la filosofía en servicio de la "tarea espiritual del pueblo alemán" (GA16, p. 113). Ciertamente, ya en Ser y tiempo se menciona al "pueblo" y a la "comunidad" (ST, p. 400), mas, Heidegger introduce estos conceptos rápidamente y sin ahondar lo más mínimo en su significado. El paso de una filosofía centrada en la individualidad hacia un pensar que pone al "pueblo", a la "comunidad", a la "polis" y a la "patria" en el centro de sus meditaciones no es para nada claro.

Pese a que en sus clases el joven Heidegger no se dedica explícitamente a tratar temas propios de la filosofía política, de ello no se desprende que hasta 1933 él no tenga una postura política. Muy por el contrario, desde el punto de vista personal es posible reconstruir la posición política de Heidegger. Tal reconstrucción es fundamental, ya que ella nos permite dar con los antecedentes que hacen posible no solo su simpatía hacia el nacionalsocialismo, sino también la relación de su filosofía con la política.

En una carta escrita el Domingo de Pentecostés del año 1917, el joven Heidegger le señala a su esposa Elfride que con su actividad docente pretende contribuir a la "enseñanza" de una "comunidad espiritual" (MlS, p. 58). En cuanto aquella "comunidad espiritual" toma la forma de una "iglesia invisible" (MlS, p. 58) es claro que ella exige un retraerse de la publicidad cotidiana. También, en una carta con fecha 14.07.1923, Heidegger repite esa intención a Jaspers cuando le comenta sobre la necesidad de establecer una "comunidad invisible" (BJ, p. 42). Como veremos, precisamente la comunidad entre profesores y estudiantes, la "comunidad educativa" (BB, p. 61) se establece no solo como el paradigma de tal comunidad, sino que además justamente a causa de este anhelo por formar una comunidad espiritual, se explica la asunción de Heidegger al rectorado en el año 1933.

La necesidad de crear una nueva forma de comunidad intelectual surge desde la visión crítica que ya el joven Heidegger tiene frente a la situación de la universidad 
alemana. En su carta del 15.06.1918 dirigida a Elisabeth Blochmann, Heidegger le comenta que "en nuestras universidades" se ha perdido "aquella línea simple y tranquila del ser espiritual y de la vida espiritual" (BB, p. 7). Tampoco se debe olvidar que en el semestre de verano del año 1919, Heidegger sostiene una cátedra con el título Sobre la esencia de la universidad y del estudio académico. En la medida en que el manuscrito de la lección se ha dado por perdido, en la actualidad solo se cuenta con los apuntes de Oskar Becker (GA56/57, pp. 205-214). En la lección de 1923 repara Heidegger con decisión: "La situación de la ciencia y de la universidad se ha vuelto dudosa. ¿Qué pasa? Nada". Y continúa: "En la actualidad ya se cuenta con una literatura propia sobre la pregunta por el cómo debería ser. Por lo demás no pasa nada" (GA63, pp. 32-33). En estas líneas, Heidegger expone su crítica con claridad; frente al estado "dudoso" de la universidad no se precisan teorías, lo que se requiere es la acción.

Por otra parte, es claro que ya para el año 1918, Heidegger está convencido de la importancia que tienen los "líderes" para la conducción de la masa:

La total confusión y oquedad y extrañeza valórica dominaron la vida nacional y la concepción de nación en general. Ahí sólo ayudan nuevos hombres que llevan consigo un parentesco originario con el espíritu y sus pretensiones y yo mismo reconozco como cada vez más urgente la necesidad de líderes [die Notwendigkeit der Führer] -sólo el individuo es creador (también en el liderazgo), la masa jamás- ya hoy en día nuestro pueblo [Volk] está mucho mucho más empobrecido espiritual y anímicamente de lo que en el futuro empobrecerá materialmente" (MlS pp. 85-86).

Para cuando Heidegger escribe esta carta, Alemania vive la llamada "Revolución de Noviembre" (1918/19) que conduce a la transformación del Imperio Alemán desde una monarquía constitucional hacia una República parlamentario-democrática. En vista de su convicción de que solo el individuo -“jamás la masa"- es creador, es evidente que Heidegger se enmarca en la línea conservadora y anti-democrática propia de su tiempo. La "necesidad de líderes" no es pues una creencia que defiende a partir de 1933, sino que ya el joven Heidegger anhela una guía que tenga "un parentesco originario con el espíritu y sus pretensiones". Precisamente una tal guía cree encontrarla Heidegger en la figura de Hitler.

Teniendo en cuenta estos antecedentes, se observa que pese a que Heidegger hasta 1933 no se concentra filosóficamente en temas políticos, en el plano personal se deja ver una postura política que se relaciona con el anhelo de una transformación de la universidad alemana tal, que permita un despliegue de la comunidad filosófica. Heidegger toma partido político por el nacionalsocialismo porque está convencido de que este movimiento trae consigo una revolución cultural capaz de contribuir con la renovación y el fortalecimiento de la comunidad filosófica. 


\section{Heidegger y el rectorado: hacia una guía espiritual}

Desde un principio es necesario dejar en claro que Heidegger no es en caso alguno un nazi en sentido tradicional. Su desacuerdo con la ideología oficial del nazismo se plasma en su rechazo de la ideología racista de Rosenberg y del biologismo de Kolbenheyers. Tampoco se puede sostener que Heidegger sea un antisemita radical. Por una parte, no se puede negar el tono antisemitista que tienen algunas de sus cartas a su esposa Elfride; mas, al mismo tiempo Heidegger mantiene buenas relaciones con judíos (con Hannah Arendt, Elisabeth Blochmann, etc.). Para Heidegger no se trata inmediatamente de "sangre y suelo" [Blut und Boden] ya que, si bien éstos son para él "poderosos y necesarios", "no son condición suficiente para la existencia de un pueblo" (GA36/37, p. 263). Más bien se precisa de una "voluntad de saber y de espíritu" (GA36/37, p. 263). Lo que para Heidegger se ubica en el centro no es la "raza alemana", sino su espíritu [der Geist].

Las primeras frases de su discurso rectoral dejan en claro que mediante la asunción del rectorado, Heidegger toma el papel de guía espiritual de la universidad de Friburgo, no para continuar con el "diletantismo" de la Alemania nazi (BB, p. 67), sino para contribuir en la construcción de una nueva Alemania, de una Alemania espiritual: "La asunción del rectorado es la obligación de la conducción espiritual [geistige Führung] de la universidad" (GA16, p. 107). Heidegger entiende a los alemanes no como una mera raza, sino como un "pueblo espiritual" [geistiges Volk] que debe asumir su "misión espiritual" [geistiger Auftrag] para así poder desarrollar su "mundo espiritual" [geistige Welt] (GA16, pp. 107-113). Lo que para Heidegger es central es precisamente contribuir a que el pueblo alemán se apropie de su espíritu. Pues, para él, solo un "mundo espiritual" le otorga "grandeza a un pueblo" (GA16, p. 112). Desde aquí es legítimo afirmar que Heidegger se vio a sí mismo como el guía espiritual de una Alemania idealizada. Jaspers nos dice con razón que Heidegger "como filósofo" en realidad quería "educar al Führer" (1978, p. 183). Sin duda alguna, a través de una revolución dentro de la universidad, Heidegger tenía por objetivo darle un fundamento espiritual al nacionalsocialismo (Pöggeler 1992, p. 204).

En las dos conferencias sobre La universidad alemana que Heidegger imparte en la Universidad de Friburgo entre el 15 y el 16 de agosto de 1934, es decir, algunos meses tras su renuncia como rector, él posiciona a la universidad como el centro espiritual fundamental para la consagración de la revolución nacionalsocialista. Aquí expone el desarrollo histórico de la universidad alemana, poniendo especial énfasis en el entendimiento que de ella se tiene en el siglo XIX. Según Heidegger, durante el paso del siglo XVIII al siglo XIX los alemanes serán muchas cosas excepto libres. "Pero, en todo ese desvanecimiento político, en toda esa división nacional, en toda esa miseria del pueblo aún vivía y vivía ya una Alemania secreta [geheimes Deutschland]" (GA16, p. 290). La "Alemania secreta" no se identifica con la Alemania fáctica sometida bajo el dominio de Napoleón. Muy por el contrario, ella es la fórmula para expresar una "nueva libertad" (GA16, p. 290) latente en el espíritu de los alemanes: "La esencia de la libertad fue comprendida de un modo nuevo, fue implantada en el saber y en la voluntad de los alemanes" (GA16, p. 290). Heidegger sostiene que 
aquella nueva concepción de la libertad se muestra en diversas dimensiones culturales: a través de la poesía alemana (de la romántica de Herder, Goethe, Schiller, entre otros), de la filosofía de Kant, Fichte, Schleiermacher, Schelling y Hegel; y de la nueva voluntad política de políticos y soldados (GA16, p. 291). "Poetas y pensadores crearon un nuevo mundo espiritual, en el que el reinar de la naturaleza y las fuerzas de la historia fueron puestos en conjunto y pensados unitariamente en la esencia de lo absoluto" (GA16, p. 291). De este modo, libertad significa "unión con la ley del espíritu del pueblo, la que se expone ejemplarmente en las obras del poeta, del pensador y del político", libertad no es otra cosa que "responsabilidad con el destino del pueblo" (GA16, p. 291).

Con el replanteamiento de la libertad durante el siglo XIX, ocurre una refundación de la misión de la universidad. En cuanto el saber y la voluntad "deben ser despertados, guiados, fijados y constantemente refundados", ellos precisan de la "educación" [Erziehung] (GA16, p. 292). Justamente "la educación del más alto saber sobre las leyes y los ámbitos de toda la existencia del pueblo ocurre en la universidad" (GA16, p. 292). Esta forma de entender la universidad exige que la filosofía se ubique en el centro de la universidad. Sin embargo, la renovación espiritual de la universidad del siglo XIX se ve interrumpida por la pretensión de la ciencia de instaurarse como una ciencia única e independiente de la filosofía (GA16, p. 295). Poco a poco, la libertad dejó de ser concebida como "unión con la ley del espíritu del pueblo" y pasó a ser un mero asunto opcional. Con ello, la universidad pierde "su propia unidad espiritual originaria" (GA16, p. 301).

A partir de este diagnóstico histórico-espiritual de la universidad alemana y por medio de su asunción del rectorado, Heidegger intenta retomar el camino iniciado en el siglo XIX. La universidad no debe ser "reformada", sino que debe recuperar "un mundo espiritual originario y unido" (GA16, p. 301). Heidegger está convencido de que tal autoafirmación de la universidad es posible gracias a la "revolución nacionalsocialista", pues ella lleva a una "transformación" de la "existencia histórico-espiritual del pueblo" (GA16, pp. 301-302).

\section{Educación del espíritu como tarea política del filósofo}

En sus lecciones de invierno de 1931/32 y de 1933/34, en cuyo centro se haya el mito de la caverna de Platón, Heidegger no sólo determina el rol del filósofo, sino que además le adjudica un rol político. El filósofo es para Heidegger el "libertador" [Befreier] (GA36/37, p. 181). El filósofo-libertador es por una parte quien cuestiona, quien tiene una actitud "que pregunta" y "que aprende" para así poder dar con lo esencial (GA34, p. 97). A través de su actitud crítica, el filósofo pone en duda aquello que en la existencia cotidiana aparece como evidente y obligatorio, para con ello dar por sí mismo con lo esencial y verdadero. A diferencia del común de los hombres que en su cotidianidad vive como los encadenados en la caverna platónica, el filósofo es 
capaz de diferenciar entre el saber aparente, como el ver las sombras de las cosas y el saber verdadero, como el ver las cosas mismas.

Ya en el semestre de invierno de 1931/32, Heidegger critica la ausencia del filósofo en materias políticas: "Ciertamente, hoy en día se dispone de veneno y de armas para matar, sin embargo, falta el filósofo" (GA34, p. 85). Mas será recién en su lección del semestre de invierno de 1933/34 donde Heidegger radicalizará su visión del filósofo como libertador, en tanto éste adquiere una misión política. De ello es prueba la aprobación de Heidegger de la noción platónica del filósofo rey. De acuerdo a Heidegger, que el filósofo sea el guía de la nación significa para Platón "que los hombres que sostienen el gobierno de la nación deben ser hombres que filosofan" (GA36/37, p. 194). Aquellos hombres son los "guardianes" [Wächter], ellos tienen que resguardar "que el gobierno y que las formas de gobierno de la nación sean dominados por la filosofía; pero no por un sistema cualquiera, sino por un saber que es el más profundo y más amplio de los hombres y de su ser" (GA36/37, p. 194). En ese saber filosófico se funda y se legitima toda medida y toda regla de la nación. También en el semestre de verano de 1942, Heidegger se muestra en acuerdo con la determinación platónica del filósofo rey. En la medida en que para él la polis exige una reflexión profunda, ella necesita de la guía del filósofo (GA53, pp. 105-106). Según Heidegger, Platón sabe que la polis "es fundada en la verdad y en la esencia del ser desde la que todo ente es determinado" (GA53, p. 106). La polis es el "lugar" [Stätte], el "polo" [Pol] donde se reúne "todo ente y todo comportamiento con el ente" (GA53, p. 106). Con ello, la filosofía se eleva como el saber más alto. Como sostiene Derrida, ella es para Heidegger "una de las estructuras fundamentales del espíritu" (1988, p. 53). La filosofía es "la pregunta por la ley y la estructura de nuestro ser" (GA36/37, p. 4), y con ello se instaura como un "saber señorial" [herrschaftliches Wissen] (GA65, p. 44).

Sin duda alguna, Heidegger se considera a sí mismo como expresión del filósofo libertador. En Contribuciones a la Filosofía, él dice explícitamente que en dicho texto se trata de conseguir una "educación" para el "pensar esencial" (GA65, p. 19). La liberación que realiza el filósofo ocurre solo por medio de la educación de otros. Cuando el verdadero filósofo descubre que en la caverna no están las cosas mismas, sino solo sus sombras, él no solo rompe su propia atadura con un saber aparente, sino que además intenta convencer a los otros de que experimenten por ellos mismos la liberación. "El que se ha vuelto libre [der Freigewordene] retorna a la cueva, él mismo debe estar en la cueva para liberar aunque sea sólo a un otro" (GA36/37, p. 183). En virtud de esto se puede sostener que la gran meta de Heidegger con su involucramiento en el nacionalsocialismo, con su énfasis en la asunción del espíritu y de la construcción de un mundo espiritual, no es otra más que contribuir al proceso de reconocimiento que cada cual debe hacer por sí mismo de su propia esencia filosófica. Pues para Heidegger filosofar es la "acción originaria" [Urhandlung] (GA27, p. 221), o como dice en otra parte, el "modo fundamental del ser humano" (GA36/37, p. 182). En consecuencia, se trata de que el hombre corriente reconozca su esencia, de que se asuma como el filósofo que es. Este llamado al reconocimiento de la propia esencia, del propio espíritu, es en realidad el llamado a la propiedad [Eigentlichkeit] de la existencia. Dicho propósito lo admite el propio Heidegger: 
Tras lo hasta aquí dicho significaría que todos los hombres deberían volverse filósofos si es que quieren existir propiamente. Eso es en tal caso verdadero, a título de que entre las muchas posibilidades de la existencia el ser filósofo significa el modo fundamental [Grundart] en el que el hombre se reconoce frente al todo de los entes y a la historia del hombre (GA36/37, pp. 186-187).

Así, se descubre que Heidegger mantiene una comprensión clásica de la filosofía. Igual que para Aristóteles, también para Heidegger la vida filosófica representa la forma más alta y más valiosa de la existencia humana.

\section{Los alemanes y los griegos}

La revolución nacionalsocialista trajo consigo un tono de cambio que llena a Heidegger con "una extraordinaria fuerza unificadora" (BB, p. 60). En el fondo, la revolución nacionalsocialista es para él una revolución cultural, es decir, una transformación radical que aspira a que los alemanes asuman su propio espíritu y con ello se hagan cargo de su destino. Heidegger cree que ha llegado el momento histórico en el que el pueblo alemán debe asumir lo que es, a saber, los herederos legítimos de la civilización griega. Como también Nietzsche y Hölderlin, Heidegger parte de la convicción de que el pueblo alemán es la continuación legítima del pueblo griego. Tras la polis griega, donde ocurre el primer comienzo de la historia y de la filosofía, ahora debe emerger la polis alemana que sea capaz de concretizar el "otro comienzo" [der andere Anfang]. Sin duda alguna, Heidegger tiene una visión idealizada de Grecia. Heidegger sostiene que el pueblo griego es "el pueblo apolítico por antonomasia", ya que los griegos no piensan la polis bajo criterios modernos. La polis no se reduce a aquello que hoy en día entendemos como "Estado". Entre 1933 y 1943, Heidegger entiende la polis griega como el lugar de la estadía histórica del hombre (GA54, p. 133). Los griegos piensan la polis desde la verdad como desocultamiento, es decir, como el lugar donde se despliega la verdad. Así pues, la importancia que para Heidegger tiene el pueblo alemán y su espíritu no se entiende sin su visión idealizada del mundo griego. Ella (y no un mero nacionalismo) es la condición necesaria para que Heidegger tome partido por el nacionalsocialismo.

En su lección Introducción a la metafísica, Heidegger sostiene que la común herencia entre griegos y alemanes se hace patente por medio del lenguaje (GA40, p. 61). Se trata, como dice Jacques Derrida, de un "privilegio del espíritu" (1988, p. 86) que comparten solo griegos y alemanes. Para Heidegger, el lenguaje muestra siempre una determinada "relación de un pueblo con el ser" (GA40, p. 55). Él sostiene que “" [e]l' lenguaje es 'nuestro' lenguaje; es 'nuestro' no sólo como el lenguaje materno, sino como aquél de nuestra historia" (GA65, p. 501). Y precisamente ésta, "nuestra historia" quiere decir "nosotros mismos en el momento de nuestra relación con el ser [Seyn]" (GA65, p. 501). A través de la legitimación de la polis griega ocurre al mismo tiempo una legitimación de la polis alemana. Pues si bien en Grecia ocurre por primera vez una relación originaria con el ser, donde la polis es fundada desde la verdad del 
ser, en tanto griegos y alemanes comparten fundamentos en una y la misma herencia espiritual-lingüística, con ello obtiene la polis alemana su legítimo derecho.

En el marco de su involucramiento político como rector de la Universidad de Friburgo, Heidegger pretende concretizar su ideal del pueblo alemán como un pueblo espiritual. Justamente en una carta del 20.01.1948, Heidegger le escribe a Herbert Marcuse: "yo esperaba del nacionalsocialismo una renovación espiritual [geistige Erneuerung] de la vida en general, una reconciliación de las contradicciones sociales y una salvación de la existencia occidental frente a los peligros del comunismo" (GA16, p. 430). En su lección sobre Schelling del semestre de verano de 1936, Heidegger afirma con claridad que el espíritu y no otra cosa es la cuestión determinante: "Y pronto debería descubrirse la profunda falsedad [die tiefe Unwahrheit] de aquella palabra que Napoleón expresa en Erfurt: 'La política es el destino'. No, el espíritu es el destino y el destino es espíritu!" (GA42, p. 3). A través de la filosofía y en relación con su involucramiento político, Heidegger quiere justamente despertar el espíritu en los alemanes, para con ello sentar la posibilidad de una nueva Alemania. Cuando se atiende a los discursos de Heidegger durante los años del nacionalsocialismo, se evidencia que él diferencia una y otra vez entre una Alemania fáctica y una Alemania espiritual. En cuanto la Alemania espiritual no se identifica con su facticidad, sino que ella solo es construida por aquellos alemanes que han asumido su espíritu, es innegable que Heidegger tiene una visión romántica de Alemania. Se podría decir que, como para Novalis, la "alemanidad" es también para Heidegger un "ideal" (Novalis 1996, p. 19). Aquella "Alemania secreta" representa aquel ideal que solo es posible de alcanzar por medio de su esclarecimiento artístico-filosófico.

En este punto es importante no olvidar que la convicción de que entre el pueblo griego y el pueblo alemán existe un lazo originario no es de cuño ni heideggeriano ni tampoco nacionalsocialista. Muy por el contrario, Heidegger se enmarca en una amplia tradición alemana. No sólo Hölderlin y Nietzsche cuentan como exponentes emblemáticos de la creencia de que "Germania", de que el pueblo alemán es el renacimiento del espíritu griego, sino que también el poeta Stefan George y su círculo de amigos [George-Kreis] se enmarcan en ésta línea. Tal como el círculo en torno a Stefan George tiene el sueño de una "Alemania secreta" que no necesariamente se identifica con la locura nacionalsocialista (no se debe olvidar que el conde Claus Schenk von Stauffenberg, quien mediante su atentado del 20.06.1944 contra Hitler representa una de las figuras más importantes de la resistencia alemana opositora del nacionalsocialismo, tenía una relación con el círculo de George), del mismo modo se presenta Heidegger con su ideal de una "Alemania espiritual".

\section{El poeta soberano}

Cuando Heidegger habla de la poesía o del poeta, él se relaciona con ello explícita o implícitamente con Hölderlin y su poesía. Para Heidegger el poeta -Hölderlin- no solo es el "fundador del ser" (GA39, p. 33), sino por sobre todo el "fundador del 
ser alemán" (GA39, p. 220). La poesía de Hölderlin se diferencia de las obras de otros poetas alemanes, pues ella es "la poesía más alemana de todas" (GA52, p. 119). De este modo y tal como afirma Peter Trawny, la poesía de Hölderlin se instaura como "única fuente [...] desde la que se puede experimentar, lo que es lo 'alemán' y quienes son los 'alemanes"” (Trawny 2004, p. 68). La poesía de Hölderlin es aquella poesía que funda la existencia histórica de un pueblo y de su verdad (GA39, p. 6, p. 220/ GA53, p. 84). Con ello, el poeta funda el lugar donde un pueblo puede vivir históricamente. Al poeta le pertence, pues, un rol fundante (GA39, p. 113). La historia de Occidente y con ello, de la filosofía, gana con la poesía fundadora de Sófocles su primer comienzo. Precisamente la poesía de Hölderlin refleja el momento de un nuevo comienzo en la historia:

La historicidad es la distinción de aquella civilización humana [Menschentum], cuyos poetas son Sófocles y Hölderlin, pues en Grecia ha ocurrido algo incipiente [etwas Anfängliches] y sólo lo incipiente funda historia. El eco del primer cántico de la tragedia Antígona de Sófocles en la poesía hímnica de Hölderlin es una necesidad histórico-poética dentro de la historia en la que se decide el estar o el no estar en casa [Heimisch - und Unheimischsein] de la civilización humana occidental (GA53, pp. 69-70).

En cuanto es el poeta y no el filósofo quien funda la verdad del pueblo, con su interpretación de Hölderlin, Heidegger quiere dilucidar filosóficamente aquel nuevo comienzo en la historia, que Hölderlin poéticamente ya ha puesto en marcha.

$\mathrm{Al}$ poeta le pertenece un estatus distinto de aquel propio del pensador, ya que su capacidad fundante va más allá de una distinción ontológica. Pues, como dice Heidegger, mientras "[e]l pensador dice el ser", "el poeta" es quien "nombra lo sagrado" (GA9, p. 312). El poeta posee un caráter sacro ya que él se halla en medio de los dioses y del pueblo, y "sólo y primariamente en ese entre [Zwischen] se decide quién es el hombre y dónde él asienta su existencia” (GA4, p. 47). Gracias a su posición intermedia, su hallarse entre hombres y dioses, al poeta le es posible comprender la palabra efímera de los dioses y formularla para una comunidad, para un pueblo. De este modo, la poesía es una "unificación verdadera del individuo en una comunidad originaria" (GA39, p. 8). Heidegger enfatiza una y otra vez el rol sacro del poeta, en cuanto él afirma que el poeta se halla en una especial relación con lo sagrado. Solo porque el poeta escucha lo que los demás hombres no pueden oir, porque se mantiene atento a la huella de los dioses ausentes, emerge su obra poética como expresión de la reconciliación entre hombres y dioses. A través de la obra poética, el poeta logra hacer explícito el coopertenencerse de dioses y hombres: "La palabra de Hölderlin dice lo sagrado y así nombra el espacio-tiempo único de la decisión incipiente para la estructura esencial de la historia venidera de dioses y de civilizaciones humanas" (GA4, p. 77). La "política" heideggeriana se relaciona, pues, no solo con la concepción platónica del filósofo rey o con su definición del filósofo como libertador, sino que además ella está en una relación directa e indisoluble con su interpretación de Hölderlin. No obstante, la interpretación heideggeriana de Hölderlin se vincula sin duda alguna con 
una determinada lectura de su poesía, a saber, con las interpretaciones que Norbert von Hellingrath y que el círculo en torno a George tienen de Hölderlin.

La admiración que siente Heidegger por Stefan George es puesta de manifiesto en diversas ocasiones. Una de las más famosas es en el semestre de invierno entre 1957/58, cuando Heidegger interpreta filosóficamente el poema de George titulado La palabra [Das Wort]. Sin embargo, ya en el semestre de invierno de 1919/20, el joven Heidegger elogia a George en cuanto este poeta es alguien "que puede ver tan inmediatamente" (GA58, p. 69). La relación de Heidegger con el circulo de George se aprecia en el hecho de que él hasta el fin de sus días cita a Hölderlin de acuerdo a la edición de Norbert von Hellingrath, quien es un discípulo y amigo de Stefan George. El enorme valor que tiene para Heidegger el trabajo de von Hellingrath como editor e intérprete de la obra de Hölderlin se plasma en la correspondencia que él mantiene con la prometida de von Hellingrath, Imma von Bodmershof. En el año 1976, le escribe: "El tomo cuarto de Norbert -usted lo sabe- está siempre conmigo" (BvB, p. 143). También en el semestre de invierno de 1941/42, Heidegger remitirá a la conferencia de von Hellingrath del año 1915 titulada La locura de Hölderlin. (GA52, p. 44). En dicha lección, Heidegger no solo cita el poema de Stefan George Norbert, poema dedicado a von Hellingrath, sino que además llama a sus estudiantes a no olvidar el trabajo de von Hellingrath -quien muere en servicio en la batalla de Verdún el 14 de diciembre de 1916- a "no volverse ciegos ante al brillo discreto de esta figura" (GA52, p. 45). Por último, no debe olvidarse que Heidegger le dedica a von Hellingrath su conferencia en Roma sobre Hölderlin (1936).

Cuando se analiza la conferencia de von Hellingrath Hölderlin y los alemanes (1915), se puede apreciar su innegable cercanía con la interpretación heideggeriana de Hölderlin. Von Hellingrath es el primero en sostener que el pueblo alemán no es el "pueblo de Goethe", sino el "pueblo de Hölderlin" (1936, p. 124). Como Heidegger, también von Hellingrath está convencido de que Hölderlin no solo es el poeta "más alemán" entre los poetas alemanes, sino que además, y "sin perjuicio de eso", Hölderlin es "con razón" el "más griego" de todos (1936, p. 129). Así mismo, también la comprensión que tiene von Hellingrath de Hölderlin como el "mediador entre lo divino y los hombres" (1936, p. 136) se vincula con la interpretación heideggeriana de Hölderlin. Por último, es notable que, también para von Hellingrath, Hölderlin es el "vidente" que tiene una especial mirada hacia el futuro (1936, p. 138).

En la interpretación de von Hellingrath sobre Hölderlin se halla en primer plano un pensamiento que es fundamental, tanto para Heidegger como para el círculo de George: el mito de que existe una común herencia espiritual entre helenismo y alemanidad. Pues, como dice von Hellingrath, pese a todas las diferencias entre griegos y alemanes, "vemos en Hellas nuestra prehistoria y pasado, ese hogar de juventud y los viejos dioses de ese hogar están de algún modo aún vivos entre nosotros, apremian por una nueva existencia y por nombres" (1936, p. 106). También George es un convencido de que la vida griega renacería en el pueblo alemán. E incluso, pese a que tanto Heidegger (GA52, p. 78) como von Hellingrath (1936, p. 105) intentan desligar su interpretación de Hölderlin de la visión propia del Idealismo Alemán, resulta bastante difícil pasar por alto el hecho de que la creencia en una cercanía entre 
el pueblo alemán y el pueblo griego tiene su fuente en la tradición alemana. En una carta a Elisabeth Blochmann del 22.06.1932, donde intenta aclarar su comprensión sobre lo político, Heidegger enfatiza la relación entre helenismo y alemanidad: "Pero precisamente así [como política partidista D.A.] yo no veo el centro -sino que yo veo Roma-Moscú y -sí- quiero decir, a los griegos, de quienes Nietzsche dijo que sólo los alemanes le están a la altura" (BB, p. 52).

La comprensión de Heidegger del poeta se vincula, sin duda alguna, con la concepción de un poeta soberano, que ambos, George y von Hellingrath, también comparten. En el poema El poeta en tiempos de confusiones, George nos dice que el poeta no solo unifica "el verdadero símbolo a la bandera popular", sino que además "guía a través de la tormenta y de señales horrorosas", él guía "a su fiel bandada hacia la obra/ del día despierto y planta el Nuevo Imperio [Neues Reich]" (2003, p. 30). Mas, el soberano, el fundador del "Nuevo Imperio", no es cualquier poeta, sino solamente Hölderlin. Y no podía ser de otro modo, en cuanto Hölderlin es para George "el gran vidente" que "aparece para su pueblo" (1998, p. 59). Hölderlin con su "vaticinio" "claro" e "imposible de descomponer" es "la piedra angular del próximo futuro alemán y el invocador del Nuevo Dios" (1998, p. 60). Al igual que George, también Heidegger sostiene que nos debemos poner "bajo la medida del poeta" (GA39, p. 4). Estar bajo la medida del poeta significa permanecer bajo su dictum. Con ello, el poeta asume el rol de soberano del pueblo alemán. Mas, tanto en Heidegger como en George, es posible dar con otra similitud: ambos integran lo religioso y lo artístico en un objetivo político. Para George, como también para von Hellingrath y para Heidegger, Hölderlin está en una "confederación con dioses y con fuerzas" (1998, pp. 59-60). La fundación de la polis mediante el poeta es así un acto político de altísimo grado, pero es de un tipo tal, que se diferencia de lo político en sentido tradicional. Se puede decir que, como George, Heidegger es político en favor de la cultura. Lo que aquí se encuentra de trasfondo es justamente la creencia de que el más alto soberano es el artista. Precisamente aquella es la convicción romántica que comparten tanto el círculo de Goerge, von Hellingrath y Heidegger. Ya Novalis afirmaba que el "verdadero príncipe es el artista de los artistas", ya que solo así "todo puede llegar a ser bellas artes" (FS, p. 57). Para todos estos "románticos" se trata de que seamos capaces de ver el mundo como una manifestación del espíritu, como una obra de arte. Pero solo en Heidegger el mito romántico se unifica con una filosofía -que siendo a la vez ontológica e histórica- exige atender y estar preparados para el momento en el que acontece lo originario. El error político de Heidegger no es solo el error de ver en el nacionalsocialismo el umbral de "otro comienzo" en la historia y en la filosofía, sino que de la mano de ello, el error romántico de creer que a la cabeza de dicho renacer espiritual se precisa del político-artista. Justamente, debido a que Heidegger ve en la figura de Hitler la encarnación de dicho político-artista, se explica lo inexplicable, a saber, su lealtad hacia Hitler y hacia su revolución. 


\section{Una "política" romántico-platónica}

A partir de lo hasta aquí analizado, se evidencia que en la conexión entre la filosofía heideggeriana y la política destacan tres aspectos:

Por una parte, a ella le es propio un cierto platonismo: para Heidegger la filosofía es el "saber señorial" capaz de sostener todos los demás saberes. Solo en cuanto la política es conducida por la filosofía, ella gana su legitimación y su forma más propia. Por tanto, su filosofía debía mostrarse como el fundamento filosófico del que carecía la revolución nacionalsocialista. Ella tenía la tarea de mostrarle al nacionalsocialismo que la centralidad del pueblo alemán no radica en un mero biologismo o en la supremacía de la raza aria, sino en la profunda conexión entre el espíritu alemán y el espíritu griego. El nacionalsocialismo representaba para Hedegger la posibilidad de que el comienzo griego reviviera en una polis alemana (Fistetti 1999, p. 7), en cuanto dicha polis fuera conducida por la filosofía. El mito de la cercanía espiritual entre helenismo y alemanidad se ve reforzado a partir del carácter eminente que tiene la filosofía para Heidegger. Pues griegos y alemanes, tal como Heidegger los entiende e idealiza, no son pueblos históricamente constatables, sino que representan la encarnación de un ideal, a saber, de la concreción de la vida filosófica. Filosofía y mito se complementan: el ideal de la vida filosófica como la forma de vida más noble de todas, sumada a la mitificación de un pueblo determinado, en el que dicho ideal es encarnado, son las fuentes directas en las que se funda el "enredo" de la filosofía heideggeriana con la política.

Tras el fracaso del nacionalsocialismo, Heidegger pierde la confianza en un nuevo comienzo capaz de concretizarse a través de la política. Él ya no cree posible que el otro comienzo sea realizable por medio de la instauración de una polis alemana. En una carta del 14.03.1974 a Hannah Arendt se deja ver el escepticismo de Heidegger frente a lo político: “A diferencia tuya le presto un interés menor a la política. En lo principal el estado del mundo está claro. El poder de la esencia de la técnica es apenas percibido. Todo se mueve en lo ostensible" (BA, pp. 247-248).

1) La vinculación explícita entre la filosofía heideggeriana y la política tiene un fondo metafísico. Durante los años treinta, Heidegger aún cree en la metafísica. Él espera que a partir de una decisión, sea posible un cambio en la historia. Se trata de que el pueblo alemán se decida por sí mismo a una "vinculación [Bindung] con la ley más interna" y con las "disposiciones de nuestra escencia" (GA16, p. 281). Solo por medio de la unión que el hombre y un pueblo sella con su destino y esencia es posible alcanzar una libertad auténtica. Ciertamente, Heidegger no entiende la libertad como un mero decisionismo, sino que ella es expresión de la asunción que hombres y pueblos hacen de su propia esencia. La libertad no es más que el "despertar y la realización de la voluntad [Wille] del pueblo para su más propia misión [Sendung]" (GA16, p. 281). Con ello, la voluntad se instaura como condición necesaria para la autoafirmación de un pueblo. Precisamente la creencia de que mediante la voluntad es posible fundar un nuevo comienzo en la historia y en la filosofía, es la creencia metafísica que durante los años treinta Heidegger 
comparte con Nietzsche, quien para él es "el último gran filósofo de los alemanes" (GA16, p. 297). Sin embargo, Heidegger descubrirá que la exacerbación de la voluntad, expresada en la fórmula nietzscheana "voluntad de poder", y con ello, de la metafísica, termina en un callejón sin salida. Con decisión propondrá el fin de la filosofía como metafísica y el inicio de un otro pensar que acceda serenamente a la verdad del ser. En tiempos del poder atómico, es decir, del creciente e imparable dominio técnico, solo resta una actitud de "serenidad para con las cosas" [die Gelassenheit zu den Dingen] (GA16, p. 527) y de lograr acceder a un habitar poético como la realización del habitar en la cuadratura.

2) La "política" heideggeriana se evidencia como un proyecto artístico-romántico: Teniendo presente las similitudes que ostentan tanto la interpretación heideggeriana de Hölderlin con aquella propia del círculo de George y de von Hellingrath, es posible observar que el nacionalismo de Heidegger se diferencia rotundamente de aquel propio del nacionalsocialismo. La tierra natal [das Vaterland] no es para Heidegger la Alemania concreta, ya que la patria [die Heimat] va mucho más allá de límites político-geográficos. Se trata de entender la patria bajo la mirada del poeta, a saber, como cercanía con el origen: "Lo más propio y lo mejor de la patria consiste solamente en ser esa cercanía con el origen, y en ninguna otra cosa además de eso" (GA4, p. 23). La cercanía [die Nähe] a la cual Heidegger hace alusión, no se refiere aquí a una pura proximidad. La cercanía no significa primariamente una disolución de la distancia. En cuanto Heidegger entiende la cercanía de un modo dinámico, es decir desde la dinámica propia de la verdad del ser, ella es el comportamiento en el que lo próximo se mantiene en una cierta lejanía. Sin embargo, en cuanto el hombre normalmente entiende la cercanía solo como lo cercano y próximo, él se concentra solo con el ente y se olvida del ser, de su dinamismo y de su especial modo de sernos cercano. Por ello, Heidegger sostiene que el "arribo a la patria [Heimkunft] es el retorno en la cercanía con el origen" (GA4, p. 23). Contribuir a que el ser humano logre tal retorno es la tarea del poeta, pues "la vocación del poeta es el arribo a la patria" (GA4, p. 28). En consecuencia, la patria, al igual que la polis, no son entendidas bajo cánones políticos tradicionales, sino que ambas son vistas desde un plano metapolítico. Patria y polis son comprendidas desde un plano eminentemente ontológico, a saber, como el lugar desde donde es experimentada la verdad del ser y donde ella es retenida como el juego que es. De este modo, la "política" heideggeriana no es en caso alguno identificable con la política propia de la ideología nazi. Mejor dicho aún: ella no es identificable con ninguna política en sentido tradicional. La interpretación heideggeriana de Hölderlin, en cuyo seno se enmarca la "política" heideggeriana, se muestra como una mezcla entre política, arte y religión: ella es heredera de una tradición romántica que idealiza al pueblo alemán como únicos herederos del mundo griego y que establece la figura del poeta como el mediador entre el pueblo y fuerzas ocultas (sus dioses). Desde aquí es posible comprender que su pensar en torno a Hölderlin haya sido calificado como la instauración de un "nuevo mito" (Grossmann 1996; Pöggeler 2001). No obstante, aquí no es posible analizar hasta qué punto es acertada la denominación de la interpretación heideggeriana de Hölderlin como una "teolo- 
gía de Hölderlin", tal como sostiene Andreas Grossmann (1996, p. 70), o como una "teología política", como, apropiándose de la expresión de Carl Schmitt, la llama Francesco Fistetti (1999, p. 29), o si ella refleja el intento de fundar una "nueva religión" como asegura Günther Anders (2001, p. 357). Aquí es fundamental dejar de manifiesto que la relación de Heidegger con la política es un asunto paradójico: es indudable que él se relaciona con lo político -con la polis, con la patria y con su poeta soberano- a causa de su simpatía hacia el nacionalsocialismo, mas Heidegger los entiende de un modo totalmente desligado de la visión oficial del nacionalsocialismo. O dicho de otro modo: la "política" heideggeriana se relaciona indiscutiblemente con el nacionalsocialismo, mas ella no se identifica con éste, ya que el origen de tal relación no es político, sino más bien filosófico-romántico.

3) Con lo hasta aquí dicho no se pretende, en ningún caso, exculpar a Heidegger de su responsabilidad política. Dicha responsabilidad no debe ser olvidada. Sin embargo, por medio de la presente interpretación ganamos un nuevo acceso a la pregunta por la vinculación entre la filosofía de Heidegger y el nacionalsocialismo. Teniendo en cuenta la "política" de Heidegger como un proyecto filosófico en el que se confunden los márgenes entre lo artístico, lo místico-religioso y lo político, es posible comprender que la conexión de su pensar con el nacionalsocialismo no significa una traición a la filosofía, sino muy por el contrario, el resultado casi necesario, no solo de ver en la filosofía el saber más alto y más noble de todos, sino de unir además tal filosofía al mito. Pues precisamente el mito de la cercanía espiritual entre griegos y alemanes es el trasfondo esencial desde el cual es posible que Heidegger haya considerado la revolución nacionalsocialista como el momento de la concreción histórica de una Alemania espiritual. Por tanto, pensar el error político de Heidegger implica no sólo concentrarse en su figura y en su filosofía (cosa que de por sí es necesaria), sino también pensarlo desde y en la tradición alemana de la que es heredero. El "caso Heidegger" nos obliga a pensar las consecuencias políticas que trae consigo toda tendencia romántica, toda instauración de un mito que exige la vinculación de la filosofía con la política, con el arte y con la religión. Por último, pensar el "enredo" de la filosofía heideggeriana con la política exige preguntar por el lugar de la filosofía y por el tipo de publicidad que le es propia. 
Referencias bibliográficas

Obras De HeidegGer

BA: Hannah, Arendt/Heidegger, Martin. Briefe 1925 bis 1975, und andere Zeugnisse. Hrsg. von Ursula Ludz. Frankfurt a. M.: Vittorio Klostermann, 1998.

BB: $\quad$ Heidegger, Martin/Blochmann, Elisabeth. Briefwechsel 1918-1969. Hrsg. von Joachim W. Storck. Marbach a. N.: Dt. Schillergesellschaft, 1989.

MlS: $\quad$ Heidegger, Martin. Mein liebes Seelchen!. Briefe Martin Heideggers an seine Frau Elfride 1915-1970, hrsg. von Gertrud Heidegger. München: Dt. Verlagsanstalt, 2005.

BJ: Heidegger, Martin/Jaspers, Karl. Briefwechsel 1920-1963. Hrsg. von Walter Biemel und Hans Saner. Frankfurt a. M./München: Piper, 1990.

BvB: Heidegger, Martin/von Bodmershof, Imma, Briefwechsel 1959-1976. Hrsg. von Bruno Pieger. Stuttgart: Klett-Cotta, 2000.

GA4: Heidegger, Martin. Gesamtausgabe, I Abteilung: Veröffentlichte Schriften 1910-1076, Band 4, Erläuterungen zu Hölderlins Dichtung. Frankfurt a. M.: Vittorio Klostermann, 1996.

GA16: Heidegger, Martin. Gesamtausgabe, I Abteilung: Veröffentlichte Schriften 1910-1076, Band 16, Reden und andere Zeugnisse eines Lebensweges. Frankfurt a. M.: Vittorio Klostermann, 2000.

GA34: Heidegger, Martin. Gesamtausgabe, II Abteilung: Vorlesungen 19191944, Band 34, Vom Wesen der Wahrheit. Zu Platons Höhlengleichnis und Theätet. Frankfurt a. M.: Vittorio Klostermann, 1988.

GA36/37: Heidegger, Martin. Gesamtausgabe, II Abteilung: Vorlesungen 1919-1944, Band 36/37, Sein und Wahrheit. 1. Die Grundfrage der Philosophie (SS 1933) 2. Vom Wesen der Wahrheit (WS 1933/34), Frankfurt a. M.: Vittorio Klostermann, 2001.

GA39: Heidegger, Martin. Gesamtausgabe, II Abteilung: Vorlesungen 19191944, Band 39, Hölderlins Hymnen "Germanien" und "Der Rhein" (WS 1934/35). Frankfurt a. M.: Vittorio Klostermann, 1999.

GA42: Heidegger, Martin. Gesamtausgabe, II Abteilung: Vorlesungen 19191944, Band 42, Schelling: Vom Wesen der menschlichen Freiheit (1809) (SS 1936), Frankfurt a. M.: Vittorio Klostermann, 1988.

GA53: Heidegger, Martin. Gesamtausgabe, II Abteilung: Vorlesungen 19191944, Band 53, Hölderlins Hymne "Der Ister” (SS 1942). Frankfurt a. M.: Vittorio Klostermann, 1993.

GA56/57: Heidegger, Martin. Gesamtausgabe, II Abteilung: Vorlesungen 1919-1944, Band 56/57, Zur Bestimmung der Philosophie. 1. Die Idee der Philosophie 
und das Weltanschauungsproblem (KNS 1919). 2. Phänomenologie und transzendentale Wertphilosophie (SS 1919) 3. Anhang: Über das Wesen der Universität und des akademischen Studiums (SS 1919). Frankfurt a. M.: Vittorio Klostermann, 1987.

GA63: Heidegger, Martin. Gesamtausgabe, II Abteilung: Vorlesungen 1919-1944, Band 63, Hermeneutik der Faktizität (SS 1923). Frankfurt a. M.: Vittorio Klostermann, 1988.

GA64: Heidegger, Martin. Gesamtausgabe, III. Abteilung: Unveröffentlichte Abhandlungen Vorträge - Gedachtes, Band 64, Der Begriff der Zeit (1924). Frankfurt a. M.: Vittorio Klostermann, 2004.

GA65: Heidegger, Martin. Gesamtausgabe, III. Abteilung: Unveröffentlichte Abhandlungen Vorträge-Gedachtes, Band 65, Beiträge zur Philosophie (Vom Ereignis) (1936-1938). Frankfurt a. M.: Vittorio Klostermann, 1994.

ST: $\quad$ Heidegger, Martin. Ser y Tiempo, traducido por J. E. Rivera, Santiago de Chile: Editorial Universitaria, 1988.

OBRAS DE OTROS AUTORES

Anders, Günther (2001), Über Heidegger. München: Beck.

Derrida, Jacques (1988), Vom Geist. Heidegger und die Frage. Frankfurt a. M.: Suhrkamp.

Figal, Günter (2006), Gegenständlichkeit. Das Hermeneutische und die Philosophie. Tübingen: Mohr Siebeck.

Fistetti, Francesco (1999), Heidegger und die Utopie der Polis. Frankfurt a. M.; Berlin; u.a: Lang.

Gadamer, Hans-Georg (1999), Neuere Philosophie. Hegel-Husserl-Heidegger. Tübingen: Mohr Siebeck. (Gesammelte Werke 3).

George, Stefan (1998), Sämtliche Werke, Band 17, Tage und Taten. Aufzeichnungen und Skizzen. Stuttgart: Klett-Cotta.

George, Stefan (2003), Sämtliche Werke, Band 9, Das Neue Reich. Stuttgart: KlettCotta.

Grossmann, Andreas (1996), Spur zum Heiligen : Kunst und Geschichte im Widerstreit zwischen Hegel und Heidegger. Bonn: Bouvier.

Jaspers, Karl (1978), Notizen zu Martin Heidegger. München u.a.: Piper.

Novalis (1996), Fragmente und Studien. Die Christenheit oder Europa. Stuttgart: Reclam.

Ott, Hugo (1992), Martin Heidegger. Unterwegs zu seiner Biographie. Frankfurt a. M.; New York: Camous Verlag. 
Pöggeler, Otto (2001), "Kultur-Kunst-Öffentlichkeit", En: Annemarie GethmannSiefert y Elisabeth Wiesser-Lohmann (eds.), Kultur-Kunst-Öffentlichkeit. Philosophische Perspektiven auf praktische Probleme. München: Fink. (1992), Neue Wege mit Heidegger. Freiburg i. B.; München: Alber.

Safranski, Rüdiger (2006), Ein Meister aus Deutschland. Heidegger und seine Zeit. Frankfurt a. M.: Fischer Verlag.

Trawny, Peter (2004), Heidegger und Hölderlin oder der europäische Morgen. Würzburg: Königshausen \& Neumann.

Von Hellingrath, Norbert (1936), Hölderlin-Vermächtnis. Forschungen und Vorträge. München: F. Bruckmann A.G.

Los textos de Heidegger aquí analizados son citados desde la Gesamtausgabe (GA) y traducidos por el autor. Ser y Tiempo constituye una excepción: Heidegger, Ser y Tiempo, traducido por J. E. Rivera, Santiago de Chile, 1998. 